\title{
Meta
}

Journal des traducteurs

Translators' Journal

\section{GÉMAR, Jean-Claude et Vo HO-THUY (1990) : Difficultés de langage du droit au Canada, Cowansville, Linguatech et Les Éditions Yvon Blais inc., 205 p.}

\section{Wallace Schwab}

Volume 37, numéro 2, juin 1992

URI : https://id.erudit.org/iderudit/004070ar

DOI : https://doi.org/10.7202/004070ar

Aller au sommaire du numéro

Éditeur(s)

Les Presses de l'Université de Montréal

ISSN

0026-0452 (imprimé)

1492-1421 (numérique)

Découvrir la revue

Citer ce compte rendu

Schwab, W. (1992). Compte rendu de [GÉMAR, Jean-Claude et Vo HO-THUY (1990) : Difficultés de langage du droit au Canada, Cowansville, Linguatech et Les Éditions Yvon Blais inc., 205 p.] Meta, 37(2), 350-350.

https://doi.org/10.7202/004070ar d'utilisation que vous pouvez consulter en ligne.

https://apropos.erudit.org/fr/usagers/politique-dutilisation/ 
GÉMAR, Jean-Claude et Vo HO-THUY (1990) : Difficultés du langage du droit au Canada, Cowansville, Linguatech et Les Éditions Yvon Blais inc., 205 p.

Un territoire abritant deux langues, deux cultures juridiques et une histoire sui generis, voilà qui ne peut manquer de favoriser l'éclosion d'un nombre impressionnant d'usages, de tournures, d'adaptations, d'emprunts en anglais et en français. En abordant les Difficultés du langage du droit au Canada, les auteurs Gémar et Ho-Thuy ne pouvaient se tromper sur le bien-fondé de la matière de leur étude. Balayée par les courants de l'histoire, des exigences géographiques et des systèmes juridiques, la terminologie juridique utilisée pour exprimer certaines réalités hybrides du Québec et du Canada porte une empreinte particulière dont les nuances et, il faut le préciser, les pièges nécessitent bien des explications. Pour cette raison, je comprends et approuve les préoccupations des auteurs au point de me sentir complice, puisqu'il me plaît à mes heures de discourir sur le même sujet.

À défaut de pouvoir consulter un grand recueil définitif et exhaustif de la terminologie juridique qui, hélas, n'existe pas encore, il y a une place certaine pour les Difficultés du langage du droit au Canada, ouvrage qui vient combler un vide réel et fournit un outil précieux pour les spécialistes de la rédaction et de la traduction juridiques. Les auteurs y recensent quelque 140 termes (pas assez par rapport aux dimensions du problème!) en suivant une méthode jurilinguistique rigoureuse où ils présentent pour chaque terme à tour de rôle: un contexte d'emploi, l'étymologie, généralement assortie d'une définition, des commentaires et des observations, puis une conclusion servant de synthèse ou de résumé de l'ensemble de la question.

En effet, la présence des Difficultés du langage du droit au Canada ne fait que souligner le besoin réel d'une entreprise plus en profondeur que le présent ouvrage pour vider cette question si énorme, mais cela dépasse de très loin le cadre évoqué ici.

$\mathrm{Au}$ plan de la présentation physique, les articles sont d'une longueur et d'une densité de contenu qui permettent une consultation rapide et efficace; bref, on fait le tour de la question en moins de deux... Par contre, en raison de son orientation «œuvre de référence», à moins que le lecteur ait un intérêt spécifique pour l'ensemble du domaine, l'ouvrage ne se prête pas à une lecture continue. Toutefois, voici quelques bons morceaux glanés au passage :

- Sauriez-vous vous retrouver dans la série synonymique : accusé, inculpé, prévenu et j'en passe ? Déculpabilisez-vous, car vous trouverez les réponses aux pages 4 à 6 .

- L'expression «assaut et batterie» relève-t-elle du droit, de la mécanique automobile ou de quoi encore? Consultez la page 27.

- Si les conseilleurs sont réputés pour ne pas toujours être les payeurs, quid du dérapage sémantique «aviseur légal»? (pages 28 et 29 ).

- Et que dire d'une décision judiciaire rendue «sur le banc»? Bonne question pour la magistrature debout ! À vous de le découvrir... 